\title{
Service provision for elderly people with long-term functional illness
}

\author{
S. Green, D. M. Girling, S. Lough, A. M. N. Ng and S. K. Whitcher
}

\begin{abstract}
A postal survey of old age psychiatrists was carried out to examine the pattem of services currently available for elderly people with chronic functional mental disorder, and to identify innovative models of care for this group. The opinion of respondents was sought regarding problems with senvice provision and additional resources that would be desirable. The majority of respondents felt that the needs of individual patients should determine whether they should be cared for by old age, general or rehabilitation services. Seventy-three per cent of respondents felt that more specialist residential care outside hospital was needed to improve the care of this group.
\end{abstract}

Recent debate has highlighted the provision of continuing care for older adults with mental illness as an area of growing concern. However, discussion has focused primarily on the requirements of those with dementia (Wattis \& Fairburn, 1996).

There is also a smaller but significant group of older adults with functional mental illness (depressive disorders, schizophrenia and delusional disorders) whose illness follows a chronic or relapsing course and who have had long-term problems. Some patients have suffered first episodes of functional illness in later life and gone on to develop chronic illness. Others have needed on-going intensive psychiatric support since long before the age of 65 and a number may have entered hospital in earlier life and stayed to grow old there, the so-called 'graduates' (Campbell, 1991).

The recent draft consensus statement from the Old Age Section of the Royal College of Psychiatrists on continuing care for older adults with psychiatric disorder made the recommendation that "the extent, reasons for and impact of the current wide local variations in NHS provision should be investigated". This is perhaps particularly true for those with functional illness for whom there has often been little coordinated planning. Individual psychiatric services have evolved their own patterns of care provision for this group, based on local factors, such as the presence or absence of long-stay hospitals. Such patients may be under the care of services for the elderly, general psychiatry or specialist rehabilitation services. In the context of "eligibility criteria" (Department of Health, 1995) there has been much discussion of the relative roles of the National Health Service and other providers, particularly social services and the private sector, in the provision of long-stay care.

Reports of hospital closure programmes (e.g. Perkins et al, 1989) have highlighted the difficulties of planning services for elderly people with severe psychiatric problems who additionally have age-related problems and become increasingly dependent. In the absence of adequate provision and planning, this vulnerable group may find themselves inappropriately placed; for example, on an acute ward or in a continuing care setting primarily caring for dementia sufferers. Alternatively they may remain in the community inadequately supported.

There has been no systematic overview of service provision for chronically functionally ill elderly people across the country. A recent survey of residential care for mentally ill younger adults highlighted geographical variation in provision (Lelliott et al, 1996). The aim of the postal survey described here was to study different patterns of care, to explore some of the reasons for these differences, and to identify innovative models of care.

\section{The study}

Questionnaires were sent to 311 consultants in old age psychiatry in England, Scotland, and Wales, identified from the membership list of the Royal College of Psychiatrists. The questionnaire consisted of a mixture of open and closed questions. Information was sought on the extent and nature of current services for the elderly with severe chronic functional disorder. Enquiries were made about the availability of specialist residential care and an open section allowed respondents to describe any innovative ways they had tried to meet the needs of this group. 
The questionnaire also sought information on the extent to which Old Age Psychiatry Services were responsible for the care of all those over 65 with functional illness. The opinions of respondents were sought regarding problems with service provision and additional resources that would be desirable.

\section{Findings}

One hundred and forty-five completed questionnaires were returned, but as a number of these were completed jointly by more than one member of a department they represented 155 consultants. Thirty-one psychiatrists returned the questionnaires uncompleted because they were not currently responsible for services for the elderly.

\section{Present facilities}

Table 1 summarises the responses regarding hospital beds currently available for this group. Enquiry about community services revealed that two-thirds of respondents had community mental health teams. Only $36.6 \%$ (53) described day hospital facilities specifically for the elderly functionally ill.

Thirty-two per cent of respondents had specialist residential care outside hospital specifically for older adults with chronic functional illness. Of the facilities described, $41.1 \%$ were provided within the private sector and another $19.1 \%$ within the voluntary sector, $20.5 \%$ were provided by social services, and $16.1 \%$ by joint health/social services.

Table 1. Summary of in-patient facilities currently available

\begin{tabular}{ll}
\hline $\begin{array}{l}\text { In-patient facility for } \\
\text { elderly functionally } \\
\text { ill people }\end{array}$ & $\begin{array}{l}\text { Respondents with } \\
\text { this type of facilly } \\
n(\%)\end{array}$ \\
\hline $\begin{array}{l}\text { Admission ward for elderly } \\
\text { functionally ill }\end{array}$ & $83(57.2)$ \\
$\begin{array}{l}\text { Admission ward specifically for } \\
\text { elderly with long-term } \\
\text { functional illness }\end{array}$ & $11(7.6)$ \\
$\begin{array}{l}\text { Mixed organic and functional } \\
\text { admission ward }\end{array}$ & $51(35.1)$ \\
$\begin{array}{l}\text { Admission ward covering } \\
\text { mixed age group }\end{array}$ & $24(16.6)$ \\
$\begin{array}{l}\text { In-patient rehabilitation } \\
\text { facilities } \\
\text { Continuing care beds for } \\
\text { elderly long-term } \\
\text { functionally ill }\end{array}$ & $20(13.8)$ \\
$\begin{array}{l}\text { Continuing care beds for this } \\
\text { group able to accommodate } \\
\text { the physically frail }\end{array}$ & $26(17.9)$ \\
\hline
\end{tabular}

Referral to elderly services from general psychiatric services

We were interested to find out about the process of referral from general psychiatry to specialist elderly services. In answer to the question "Are elderly patients with long-term functional illness referred on to your service from adult psychiatry?", $30.3 \%$ (44) described a process of automatic referral, $42.8 \%(62)$ reported that such patients were often referred, and $26.2 \%$ (38) reported that they were occasionally referred. Only one respondent said that such patients were never referred to the elderly service.

To try to establish the view of old age psychiatrists we asked, "Who should be responsible for this group?"; $18.6 \%$ (27) felt that old age psychiatrists should always be responsible and only $1.4 \%$ (2) felt general psychiatrists should be responsible for elderly people with chronic functional illness. A majority, 64.1\% (93), felt that either old age or general psychiatrists should have responsibility according to the needs of the patient; $21.4 \%$ felt that general psychiatrists should remain involved if the patient is known to their service.

Respondents commented on various criteria for referral from general to old age psychiatric services. One obvious criterion is that of age, but elderly people were referred automatically at a given age in less than a third of cases. Several respondents who did receive referrals automatically commented that the "cut off age was 70 or 75 , while another who received referrals automatically at 65 commented that 70 or 75 would be more appropriate. The most common reason for referral described was the development of age-related disability such as physical frailty or dementia. Another reason for referral was stability of the patient's condition to the point where residential or EMI residential care is more suitable.

In a number of services the 'graduate' schizophrenic population is more likely to remain under the care of general or rehabilitation teams. There were comments that responsibility for the care of this group particularly is very contentious.

It was evident that the majority, $64.1 \%$, of respondents believed that referral to services for the elderly should be managed flexibly depending on the individual needs of the patient. The question of resources was raised frequently with several expressing the view that, if adequately resourced, old age psychiatrists should usually become responsible. Resources for rehabilitation were particularly an issue.

Local factors influencing service

One hundred and thirteen respondents (77.9\%) reported that historically there had been a large 
psychiatric hospital in their area. Of these 100 $(88.5 \%)$ had either closed completely or had reduced beds significantly. Sixty-eight respondents $(46.9 \%)$ reported that in-patient bed numbers for the elderly with functional illness had been reduced.

Those who responded that there had been a reduction of beds for the elderly functionally ill were invited to comment on how this had been achieved. The most common response (41\%) was that patients had been discharged to other residential settings (often private) or in a few cases to group homes; $14.7 \%$ described bed reduction in conjunction with improved community care. Careful discharge planning was highlighted as important in ensuring successful residential placement, $23.5 \%$ indicating that there had been a reduction in beds for this group without adequate reprovision being made.

Comments were invited and included the following:

There was no clear cut planning for this group and they fell between adult psychiatric services ... which did not want them and psychogeriatric services where planning was mainly for the elderly organic patients. They are a neglected group."

"By closing wards and placing elderly people in residential homes many of which have not been successful placements."

"Beds closed. No functional reprovision."

"With no extra services."

\section{Perceptions of current services and additional resources needed}

Although only a minority (17.9\%) of respondents felt that a significant number of communitydwelling elderly functionally ill patients would be better placed in hospital, there was clearly widespread concern about the adequacy of care both in residential settings and in patients' own homes.

Concerns regarding residential care centred around the adequacy of care given, lack of trained staff and structured activity and the fact that such patients are often inappropriately placed with dementia sufferers.

Examples of concerns raised were the following: "I have reservations about the adequacy of care given to those patients with chronic functional illness living in 'ordinary' residential care homes. I believe their needs tend to be overlooked. Withdrawn patients tend not to come to the notice of health professionals and those with behavioural problems are often not well managed".

"[They were] transferred to residential homes on closure of the mental hospital and really require nursing skills, regular medical review and occupational therapy."

"Community support is virtually non-existent. Training for carers and staff has not happened, so many elderly people with functional illness are being looked after by people who do not have any understanding of their illness."

"Reluctantly they have to be accommodated in private EMI nursing homes with advanced dementia sufferers in order to receive trained psychiatric nursing care."

One respondent comments positively "We have relocated several from 'Part 3' to group living in the community where [they become] much more settled/less psychotic".

Concern was also expressed regarding the plight of those living independently in the community.

For example, respondents comment:

"A few patients who did well before the closure of the old mental hospital spend their time either on acute wards or disorganised in the community (e.g. sleeping rough, Bed \& Breakfast)."

"They would benefit from asylum and not [being] exposed to inner city life. Acute admission or dementia ward not an appropriate placement."

"They cause incredible problems and resource utilisation often requiring frequent admissions, changes of residence etc. Often admission causes stabilisation of mood and improves quality of life even on a long stay ward for dementia patients."

Stress to families and carers was raised as a significant issue in this context.

Table 2 illustrates responses to the question "Which of the following do you think would be highly desirable in your area to improve the care of this patient group?".

Several respondents made the point that they needed not just more in-patient beds but facilities separate from those for patients with organic illness, and it is clear from comments made in other parts of the survey that the lack of

Table 2. Summary of additional facillities regarded as desirable

\begin{tabular}{ll}
\hline & $\begin{array}{l}\text { Number of respondents } \\
\text { belleving this highly } \\
\text { dealrable } \\
n(\%)\end{array}$ \\
\hline $\begin{array}{l}\text { More in-patient beds } \\
\text { More speciallst residential } \\
\text { care outside hospltal }\end{array}$ & $\begin{array}{c}26(17.9) \\
\text { More commun (73.1) } \\
\text { mental health based }\end{array}$ \\
$\begin{array}{l}\text { Improved communication } \\
\text { and hand-over from adult } \\
\text { services locally }\end{array}$ & $67(46.2)$ \\
$\begin{array}{l}\text { Improved communication } \\
\text { and liaison with social } \\
\text { services }\end{array}$ & $56(38.3)$ \\
$\begin{array}{l}\text { Improved communication re. } \\
\text { Patients moving into area }\end{array}$ & $47(32.4)$ \\
\hline
\end{tabular}


dedicated resources for this group is a recurrent source of concern.

\section{Innovative models of care}

A significant number responded positively to the question "Have you tried any innovative ways of meeting the needs of this patient group or models of care not specified above?". Most models of care described fell broadly into three categories.

The first category concerned specialist residential care, supported housing and community group homes. In one service two in-patient units had been established in purpose-built wings of social services residential homes with acute admission beds for the elderly with organic and functional illness and limited continuing care. Patients with functional illness mixed with residents in the main body of the home. A scheme called 'Home from Home' was described where a landlady would take patients to live on her premises supported by funds from social services and by psychiatric services. In another district a 22-bed NHS hostel ward had been created and sheltered housing established with accommodation provided by the local authority and resident staff by the NHS.

A number who had developed specialist facilities for this group commented on difficulties they had experienced. These included funding issues complicating joint ventures with social services. Another respondent described two attempts at working with the private sector failing as a result of slow accumulation rates and suggested the need for an initial bridging fund from purchasers.

The second category broadly described services aiming to support this group in ordinary residential settings, such as community liaison nurses or community psychiatric nurses who specifically follow up those in residential care and nursing home care. Related to this, a number mentioned good liaison with social services and private units with good back-up from psychiatric services as an important factor in successfully placing functionally ill people. Working informally with one or more residential or nursing homes (often within the private sector) can result in a unit which takes a special interest in this group and gradually develops expertise.

The third group described various models of community support, such as intensive home nursing, along the lines of 'hospital at home' for patients with functional illness, community teams who offer 24-hour care to these patients in whatever setting, companion services, consultant-led groups, a psychotherapy service for older people and specialist day care. Good liaison with other agencies especially generally practitioners was highlighted as an important factor in caring for this group in the community.

\section{Comment}

These results highlight the need for coherent planning for chronically functionally ill elderly people involving cooperation between a number of agencies. These patients are often present in small numbers and their needs are highly varied, hence they are often slotted into the available sevices inappropriately. Sometimes appropriate services are in place for such patients within services for younger adults. It would seem highly undesirable that those who would benefit from group homes, specialist day care and indeed inpatient care with younger adults should be denied this on the grounds of age alone. There is a clear need for general, rehabilitation and old age services to cooperate flexibly to provide a range of facilities tailored to individual patient needs which can be reviewed as individuals become more frail and develop age-related problems.

The role of continuing-care NHS beds for the long-term functionally ill is unclear and there may well be strong arguments for long-term NHS care for a small proportion of this group who cannot be discharged from hospital. However, this survey suggests that such specialist beds are not available in many areas and in fact the majority of respondents perceived a greater need for residential care specifically for this group. Many expressed concern about those currently placed in unsuitable settings. Specialist residential care is available in some areas and seems to be mainly within the private sector. Again this raises issues of good liaison and cooperation between psychiatric services and other providers. Old age psychiatrists must consider how they can use their expertise and the resources available to them to facilitate good care for this group in a variety of residential settings including their own homes.

Issues of resources and financing are never far away and separation of budgets may make cooperation and joint ventures more fraught with problems than they might otherwise be. Respondents raise this as an issue both in the context of relationships between adult and elderly services and in the context of joint planning with social services.

There would be clear benefit in further evaluation of group homes and specialist residential care currently in place for this group, and of other models of care that are being implemented in different areas, facilitating sharing of innovative ideas and development of appropriate strategies for this group.

\section{Acknowledgements}

The authors would like to thank all those who gave their time to complete this questionnaire, 
Ruth Halstead, Jacqueline Hewitt, Linda Klose, and Marie McBreen for administrative help, and Dr Tom Dening for his comments on the manuscript.

\section{References}

CAMPBell. P. C. (1991) Graduates. In Psychiatry in the Elderly (eds R. Jacoby \& C. Oppenheimer), pp. 779818. Oxford: Oxford University Press.

DEPARTMENT OF HEALTH (1995) NHS Responsibilities for Meeting Continuing Health Care Needs. HSG (95) 8. London: HMSO.

LELLOTT, P., AUDIN, B., KNAPP, M., et al (1996) The Mental Health Residential Care Study: classification of facilities and description of residents. British Journal of Psychiatry, 169, 139-147.
Perkins, R. E., King, S. A. \& Hollyman, J. A. (1989) Resettlement of old-long-stay psychiatric patients: the use of the private sector. British Journal of Psychiatry. 155. 233-238.

WATTIS, J. P. \& FAIRBURN, A. (1996) Towards a consensus on continuing care for older adults with psychiatric disorder. International Journal of Gerlatric Psychiatry. 11. 163-168.

Sue Green, Research Assistant; *Deborah M. Girling, Consultant in Old Age Psychiatry; Sinclair Lough, Principal Clinical Psychologist; Annie M. N. Ng, Head Occupational Therapist; and Sarah K. Whitcher, Nurse Manager, Psychiatric Services for the Elderly, Springbank, Box 311, Addenbrooke's NHS Trust, Fulbourn Hospital, Cambridge CB1 $4 E F$

*Correspondence

\section{College Seminars Series

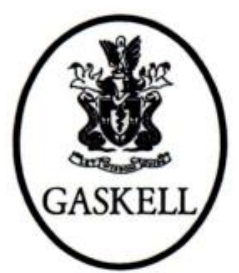 \\ Seminars in

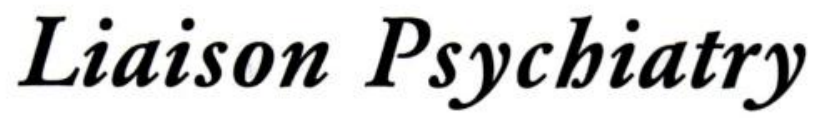 \\ Edited by Elspeth Guthrie and Francis Creed}

Moving from the psychiatric in-patient and out-patient settings to the general medical wards can be disorientating and difficult. The clinical problems are different. In this text, recognised experts in liaison psychiatry guide the trainee through the various difficulties of interviewing, assessing and formulating the psychological problems found in patients in general medical units. $f 15.00,3 / 2$ pp., 1996, ISBN 0902241958

Available from good bookshops and from the Publications Department, Royal College of Psychiatrists, 17 Belgrave Square, London SWIX 8PG. Credit card orders can taken over the telephone $(+44(0) 17 I-235235 I$, extension 146).

The latest information on College publications is on the INTERNET at:http://www.demon.co.uk/rcpsych/ 